\title{
Experiential Learning Approach to Teach Content Courses in an EFL Teacher Education Program
}

\author{
Ista Maharsi ${ }^{1}$ \\ ${ }^{1}$ Universitas Islam Indonesia, Yogyakarta, Indonesia \\ Email: ista.afandi@gmail.com
}

\begin{abstract}
This study explores the implementation of experiential learning approach in a four-credit Classroom Management course in an EFL teacher education program. There were 74 students participating in this study. The experiential learning cycle follows that of Kolb's theory which consists of concrete experience, reflective observation, abstract conceptualization, and active experimentation. Real-class observations, reflection on the observation results, discussions on the emerging problems in the field, and simulations were the series of activities that students did. Data were collected from observations, documents, and student reflective notes. Results indicate that students show positive attitudes on the implementation of experiential learning. The students can relate what occurs in the field of an English class and what should occur in such a class. They make attempts to bridge the gap between theory and practices and reflect them for their own teaching simulation. The observation stage serves to activate their knowledge on classroom management and simulation becomes the final process of conceptualization of what they believe about managing a class. This study implies that experiential learning is beneficial for learners in such a way that they can connect abstract theories and concrete experiences through experimentation and reflection. Experiential learning gives opportunities to learners to synergize knowledge and environment while adapting and experiencing. From this point, students can re-construct their understanding based on the reflection process into a new understanding and re-start the experiential learning cycle. Several recommendations for further research are discussed.
\end{abstract}

\section{Keywords: Kolb's theory; experiential learning; classroom management;} simulation

\section{INTRODUCTION}

Learning processes have been changing at all times shifting from the traditional learning to the so-called critical pedagogy or social constructivism. Once teachers were the source of knowledge while students were the knowledge receiver [1]. Books, articles, and lecturers were the available media for learning with teachers' role as the knowledge constructors [2]. However, learning may only take place in a favorable environment. In other words, learning is likely to take place at its best 
circumstance when "there is dialectic tension and conflict between immediate, concrete experience and analytic detachment" [3]. It can then be implied that learning has shifted the roles of media, teachers, students, environment, and pedagogy. The new critical pedagogy, therefore, positions learners as the knowledge constructors because learning becomes more student-centered.

Related to the new critical pedagogy, teachers should correspondingly adjust their teaching strategies to the ones supporting the student-centered paradigm. In this case, teachers play roles as the facilitators, motivators, and navigators. It is the students who learn, take most of the time for getting more experiences, and become the active knowledge seekers. As teachers are no more the only source of information, compromise between what teachers know and what students experience during the learning process may become an interesting way understand how students internalize their learning. Learning through experience, therefore, could be an alternative for facilitating students to get better learning achievement.

According to Kolb \& Fry, there are four implications of the experiential practices - the integration of the cognitive and socio-emotional perspectives on learning, the role of individual differences in learning style, the concept of growth and development inherent in the experiential learning model, and a model of learning environments that is appropriate with the experiential learning process. Learning is resulted from the process of understanding concreteness and abstractness, learning styles that fit into different individuals and experiential processes that give direction of growth and development [3]. In short, experiential learning emphasizes on several learning domains such as cognitive, behavioral, and socio-emotional factors.

Some investigations on experiential learning have been conducted in many fields of study. An experiential learning cycle was applied to improve Japanese university level students' oral communication skills. Four experiential learning cycles (planning, doing, observing, reflecting) were employed, video recorded, uploaded onto the wiki, and then subsequently used to identify and self-reflect any oral communication changes. Results from the transcript of the videos show that there was improvement in syntactic, pragmatic, lexical, and fluency of the students' oral communication skills. In addition, improved independence and confidence as well as positive attitude towards the instructional classroom activities indicate positive responses of the experiential learning cycle [4]. Similarly, cases and simulations are perceived as meaningful instructional methods in business policy subject although simulations are indicated to be less superior to cases [5]. Another study finds out that simulation modelling is also indicated to increase dynamic knowledge and promote higher order abilities. In addition, experiential learning enables students to better understand complexities of a subject or a course [6]. Many positive results are indicated in the implementation of experiential learning. However, few critiques are postulated to experiential learning in that reflection (as one component of the experiential learning cycle) can occur in relation to not only observation but also at other stages. In addition, learning is also perceived as non-automatic [7]. Likewise, experiencing, reflecting, and thinking are the elements of the same process of learning that includes rhetoric and arguments. The process of learning relates with 
others; therefore, it should also involve others [8]. Above all, despite the critiques on Kolb's theory of experiential learning, learning cycles are likely to occur through concrete experience, reflective observation, abstract conceptualization, and active experimentation although during the process the thinking, reflecting, and experiencing may intertwine in such a way that make learning happen.

Although experiential learning has been extensively used in various fields such as geography [9], food service [6], teaching using technology [10], and strategic management [11], little is known that similar research is conducted in a particular course such as Classroom Management (a content course which is taught to English language department students).

This research is aimed to describe how a four-credit content course in a teacher training program (Classroom Management) is designed to follow Kolb’s experiential learning model including the objectives and the learning activities and how students perceive them.

\section{LITERATURE REVIEWS}

Experiential learning theory views that ideas are resulted from the formation and reformation of thoughts through modified experiences. Effective learners should comply with four kinds of abilities namely concrete experience abilities (CE), reflective observation abilities (RO), abstract conceptualization abilities (AC), and active experimentation (AE) [3]. This theory highlights the importance of experience through the four cycles and that students should be trained to relate the links between those stages. In addition, two axes can be drawn from those four stages-abstract conceptualization-concrete experience (AC-CE) dimension and an active experimentation-reflective observation (AE-RO) dimension [9]. Experiential learning can also be defined as involving learners in concrete activities that make them experience the subject they are learning and later on making reflection on what they have done. Experiential learning may involve activities related to the cognitive (information/concepts), behavioral (developing skills), and affective (examining beliefs). Case studies and jigsaw learning can be considered as kinds of activities for experiential learning [13]. The use of cases in undergraduate classes was used to serve as the tool for understanding and assessing different kinds of situations in traditional classrooms. However, the shift and dynamics of the class situations make the case alone cannot meet the criteria for students' knowledge, experience, and facing real world preparation [11]. Therefore, it can be concluded that the first two elements demonstrate how concepts or information are brought to concrete experiences or understanding, while the last two elements show how the understanding is then brought to transformation. Such concrete experiences may stand as the basis for reflecting and making sense of the abstract concepts that are previously understood. Transformation, in addition, may be tricky to measure, yet in a simpler way transformation can be the most likely consequence of abstract conceptualization, concrete experience, and reflective observation, and can take the 
form of new understanding and new action. It is at the cycle of simulation that transformation may start to encapsulate.

In this study, classroom simulations are applied after the previous three activities - understanding theories, observing, and reflecting. A classroom simulation can be defined as "a method of teaching/learning or evaluating learning of curricular content that is based on an actual situation." Simulations provide a model of a dynamic system where students learn through solving problems and making decisions. It is an activity that engages students in learning through a real-life replication in which students are trained to respond to such situations by analyzing, responding, and predicting future problems. It can also be used in any level of education but teachers must be aware of the complexities of the simulation that should be suited with the students' age. The “debriefing” sessions are also important during and after the simulation in order that the simulation is planned and focused on the learning outcome of the course [14]. It can then be implied that simulations should be designed in such a way that problem solving and decision making exist, engagement is important, and debriefing sessions should be available to achieve the learning outcome.

There are two types of simulation-role-playing and system dynamics simulations. Role-playing simulations enable students to play a role in an imitated real-situation yet such a condition is assumed as real-world by the students in a way that they can train to solve problems and make decisions. In simulations, students' identity is changed by the role they are assigned and that their roles may encourage them to act deliberately without limit which consequently have the potentials to make the simulations vivid. It is through this simulation that the students can make sense of how the real-world work, then make hypotheses of what may occur due to the decisions that they make. In comparison, system dynamics simulations are principally computer-driven simulation in which information and situation are provided by the computer program and the students respond and make decisions which are put into the computer [14]. This study opt for role-playing simulations in classroom in which students are given roles as teachers and students and they have to act according to the roles they are assigned. The target of the simulation is that teachers can apply, respond, and solve problems related to classroom management.

\section{RESEARCH METHOD}

Classroom Management is a four-credit course offered to the students of English Language Teaching Department in semester 4. This class regularly meets twice a week for 100 minutes each for 28 meeting in total. The learning process was designed for students to master the issues related to how to manage classroom such as classroom disciplines, time \& space management, instructional strategies, rewards \& punishment, teacher-student relations, teachers' stress \& feeling, and students' behavior. The cognitive stage was scaffolded during the first 8-week meetings. The next 7 meetings were allocated to observing English classrooms in high schools they 
have access into such as the students' previous high schools, or the schools which have agreement and collaboration with the institution.

Prior to field observations, students were to get access to the school through informal talk to the English teachers. When the English teachers agreed, the students prepared a letter of permit from the faculty and sent it to the schools. On the observation day, the students filled in the observation sheet in accordance with what was going on during the learning processes. If allowed, the class was recorded.

After the observation period was over, students were required to submit a report and present their findings in front of their peers. Students worked in groups and presented their findings and related with the relevant theories that may support the findings. Students were to relate what the theory and practice as well as critically evaluate what occurred in the class they observed. Meanwhile, the rest of the sessions were used for simulation of managing classrooms by the students.

Students were divided into 4 groups and each group consisted of 10 students. The students chose two students who would act as teachers while the rest played roles as students. The students' roles were determined by the lecturers and the situation was written in role cards. The roles given to the students were aimed to create like-real class situation in which there were many kinds of students such as smart, lazy, diligent, helpful, silent, shy, disturbing, and trouble maker students. The situation was created so as to reflect the real class or close to the situation in real classes.

Data were taken from the observation, students' reflective notes, and documents. Videos on the learning activity was also used as the document of the program implementation. This study particularly focuses on how a content course can be

designed following a learning cycle of Kolb and how students perceive the learning activity.

\section{FINDINGS AND DISCUSSIONS}

The following are stages of implementing Kolb’s learning cycle in the research context: 


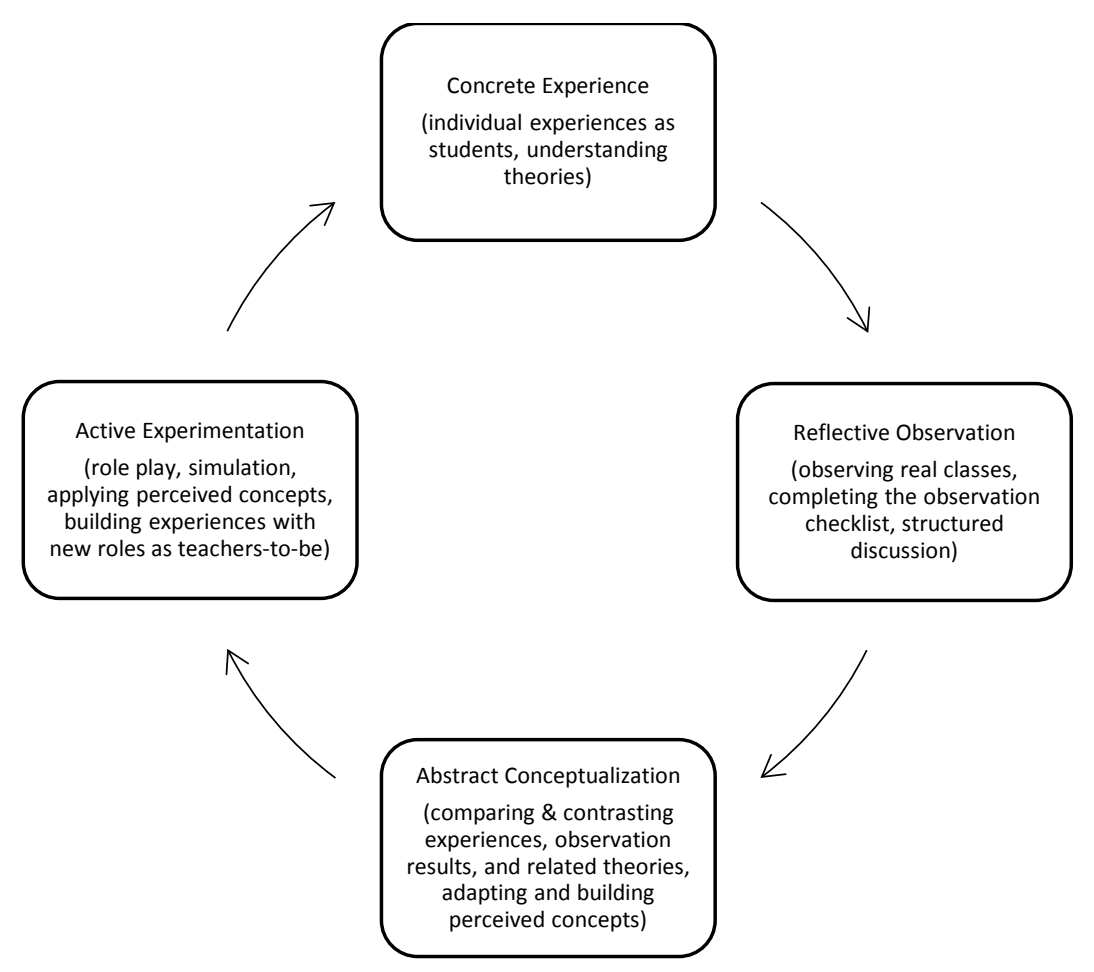

Figure 1. Adapted Kolb’s theory in the research context.

The cycle of the learning in this study starts from the concrete experience in which students have had previous encounter as high school students. They must have felt how their previous teachers acted, responded, and managed the learning although they might not have understood how it should have worked. In the design of this study, students were required to understand theories of managing classrooms through various learning activities such as reading, making concept maps, and discussing related topics. With their understanding of theoretical grounds of managing classrooms, they were then required to go to the field by doing observations in high schools. Students were to complete observation checklists and collect any significant moments during the observation. Following the observation notes, they discussed in groups what they had observed and learned from the fields and prepared for presentation sessions where they had to share the results of the observations and their corresponding views on related issues. The next cycle is abstract conceptualization which consists of comparing and contrasting experiences they had from the field, previous experiences, and their peers' experiences as well. To support this activity, students had to relate with theories and evaluated what occurred in real classrooms and what were supposed to occur in ideal classrooms. Such an activity leads them to build perceived concepts of managing classroom. The perceived concepts were rooted from their previous experiences, their observations, and their understanding of ideal concept in managing classrooms. Once they had the concepts, they were ready for the next cycle-active experimentation in which they did simulation and role 
plays while applying the perceived concepts and thereby built new roles as teachersto-be. What is more interesting is that when the cycle continues, the concrete experience may change as they become teachers as their profession. The cycle, therefore, will go on and repeat all the components in such a way that learning occurs as knowledge is transformed through experience.

Kolb's theory supports the teaching practices for any disciplines to cover the cognitive as well as behavioral psychology [9], the implementation of experiential learning in Classroom Management course is no exceptional. Students' learning activities which involve theories, observations, plans, reflections, and simulation are assumed to support the knowledge being transformed into experiences.

This study indicates that students show positive attitudes on the experiential learning cycle in Classroom Management course. The students can learn from the field of an English class through observations and describe the ideal classroom management. At this stage, they are trained to select the appropriate theories and apply their idealism through their teaching simulation. This study also reveals that the most important and helpful learning activities during the course were observation and simulation, and then followed by concept mapping. Experience which is grasped through apprehension and transformed into intention through reflective observation results in divergent knowledge while experience grasped through apprehension and transformed though extension leads to acommodative knowledge [3]. It is, therefore, expected that with such an experiential learning model, students are able to grasp knowledge, transform it either through intention or extension so that learning does take place. In their reflective notes, students elaborate how observation and simulation have helped them understand classroom management better. Many positive responses are given to observation activities. Some of the positive traits of observation include: see real classroom, learn how to manage class, give insights that in the real class not all teachers can take the appropriate responses in handling students' misbehavior, show that teachers need to choose appropriate teaching strategies, helpful for visual students, learn from experiences, understand many kinds of classroom conditions, enable students to relate the theories learn in the class and in the fields, enable students to picture how real class can be so different from the others in term of discipline, allow students to directly see the natural interaction between teachers and students, allow students to observe how students behave to teachers and how teachers handle such behavior, allow students to understand real classes where sometimes many violations of rules occur (i.e. discipline issues, teachers' lack of preparation).

Quite in the same way, simulation brings many benefits for students such as experience to be a teacher, how to manage classes, how to respond to a certain kind of student, help apply theories into practices, obtain lots of information in term of behaving in front of students, effective way to train mental ability when facing students with different characteristics, helpful for visual students, feel how real classes work, know how it feels to teach a class with many categories of students, provide knowledge and help understand what to do to handle troublesome classes and quiet classes, challenge for doing role play, play roles and do practices can 
promote better understanding, show how to control emotion, help increase selfconfidence, help improve self-ability to become future teachers, teachers should be able to control emotion and possess good adaptation skill, negative sides: exaggerate roles played by students, make students aware that becoming a teacher needs patience and coolness, allow students to reflect to their previous experiences (high school), allow students to evaluate whether what is going on is appropriate or not thereby enabling the students to respond correctly to a certain classroom behavior and prevent from unexpected occurrence, allow pre-service teachers to know how to manage classroom early on, allow students to feel how to become a teacher, allow students to prepare for future professional development from the very beginning, real class description because students can connect the dot between theories and practices, allow students to understand teachers' role in classroom, help students perceive how to become a good teacher (how to manage classroom, how to teach, how to handle misbehaved students, etc.), identify difficult handling of students' misbehavior, help define good teachers, make sense of a particular class behavior (i.e. only boy classes, vocational school condition, etc., help students prepare for their PPL (field study) at schools and KKN (community service).

Experiential learning is signified by the knowledge that is obtained as the students are involved in activities in the learning cycles [3]. In this design of the Classroom Management course, students were involved in doing the observation sessions in real classrooms and do some simulations in classrooms after they have experiences from the previous observations. Besides, their reflections on previous experiences as students can significantly help them undertsand concept in a better way than before.

"Experiential learning exists when a personally responsible participant (s) cognitively, affectively, and behaviorally processes knowledge, skills, and/or attitudes in a learning situation characterized by a high level of active involvement" [15]. In Classroom Management course, the students were actively involved in cognitive and affective learning activities. The cognitive activities involve theory mastery prior to observation, reflection, and simulation to set the ground for students' better knowledge understanding. The affective learning activities, in addition, can be identified when they were doing the observations and simulations. It can be proven from the way they respond enthusiastically to the process of before, during, and after the observation and simulation. Class situation during the simulation activities were vivid and engaging. Students are also given opportunities to give comments and feedback to their classmates' simulation which in turn helps activate the students' reflection ability.

To evaluate whether the course activities align with the principles of experiential learning formulated by the Association for Experiential Education [16], a list of checlists are made (Table 1 ). 


\section{TABLE I. PRINCIPLES OF EXPERIENTIAL LEARNING FORMULATED BY THE ASSOCIATION FOR EXPERIENTIAL EDUCATION [16]}

\begin{tabular}{|c|c|c|c|}
\hline $\begin{array}{c}\text { Principles } \\
\end{array}$ & Yes & No & Remarks \\
\hline $\begin{array}{l}\text { Experiential learning occurs when } \\
\text { carefully chosen experiences are supported by } \\
\text { reflection, critical analysis and synthesis. }\end{array}$ & $\checkmark$ & & $\begin{array}{l}\text { Critical analysis and } \\
\text { synthesis are embedded in the } \\
\text { observation reports and mini } \\
\text { essay serving as the final } \\
\text { assessment }\end{array}$ \\
\hline $\begin{array}{l}\text { Experiences are structured to require the } \\
\text { student to take initiative, make decisions and } \\
\text { be accountable for results }\end{array}$ & $\checkmark$ & & $\begin{array}{l}\text { Taking initiatives and } \\
\text { making decisions are visible in } \\
\text { the simulation session }\end{array}$ \\
\hline $\begin{array}{l}\text { Throughout the experiential learning } \\
\text { process, the student is actively engaged in } \\
\text { posing questions, investigating, } \\
\text { experimenting, being curious, solving } \\
\text { problems, assuming responsibility, being } \\
\text { creative and constructing meaning }\end{array}$ & $\checkmark$ & & $\begin{array}{l}\text { Simulations require them } \\
\text { to experiment, solve problems, } \\
\text { responsible, creative, and } \\
\text { construct meaning }\end{array}$ \\
\hline $\begin{array}{l}\text { Students are engaged intellectually, } \\
\text { emotionally, socially, soulfully and/or } \\
\text { physically. This involvement produces a } \\
\text { perception that the learning task is authentic. }\end{array}$ & $\checkmark$ & & $\begin{array}{l}\text { Intellectual, emotional, } \\
\text { social, and physical bound } \\
\text { presents. }\end{array}$ \\
\hline $\begin{array}{l}\text { The results of the learning are personal } \\
\text { and form the basis for future experience and } \\
\text { learning }\end{array}$ & $\checkmark$ & & \\
\hline $\begin{array}{l}\text { Relationships are developed and } \\
\text { nurtured: student to self, student to others and } \\
\text { student to the world at large }\end{array}$ & $\checkmark$ & & \\
\hline $\begin{array}{l}\text { The instructor and student may } \\
\text { experience success, failure, adventure, risk- } \\
\text { taking and uncertainty, because the outcomes } \\
\text { of the experience cannot totally be predicted. }\end{array}$ & $\checkmark$ & & $\begin{array}{l}\text { The observation sessions } \\
\text { and the simulations do take } \\
\text { time and risk-taking. Some } \\
\text { students felt quite tense } \\
\text { because of the classroom } \\
\text { situations in the field and } \\
\text { during the simulations. This } \\
\text { shows that students are not } \\
\text { totally ready and therefore such } \\
\text { learning activities are of } \\
\text { important experiences before } \\
\text { they really teach in real } \\
\text { classrooms. }\end{array}$ \\
\hline $\begin{array}{l}\text { Opportunities are nurtured for students } \\
\text { and instructors to explore and examine their } \\
\text { own values }\end{array}$ & $\checkmark$ & & \\
\hline $\begin{array}{l}\text { The teacher's primary roles include } \\
\text { setting suitable experiences, posing problems, } \\
\text { setting boundaries, supporting students, } \\
\text { insuring physical and emotional safety, and } \\
\text { facilitating the learning process. }\end{array}$ & $\checkmark$ & & $\begin{array}{l}\text { Supports also come from } \\
\text { department and the faculty }\end{array}$ \\
\hline $\begin{array}{l}\text { The teacher recognizes and encourages } \\
\text { spontaneous opportunities for learning }\end{array}$ & $\checkmark$ & & \\
\hline
\end{tabular}


TABLE I. Cont.

Teachers strive to be aware of their biases, judgments and preconceptions, and how these influence the student

The design of the learning experience includes the possibility to learn from natural consequences, mistakes and successes.

The learning experience such as learning from mistakes and successes occur now and then and this makes the students experience more than once

From table I, it can be concluded that the course design in this study follows the experiential learning of Kolb in which the learning cycle consisting of 4 aspects are all included in the learning cycle and the activities accord with the principles determined by Association for Experiential Education.

\section{CONCLUSION}

This study highlights the many benefits of experiential learning cycles to teach Classroom Management course. When appropriately designed, adapted, and implemented, the experiential learning cycle can become a good alternative to lead students to bridge the theories and practices through knowledge understanding, observation, experimentation, and reflection. What students learn in classrooms was activated when they observed how classroom management was implemented in real classrooms by other field practitioners (real classroom teachers). When they had to manage their classrooms in a simulation, they re-constructed and synthesized what they knew and what they saw in the fields into their new belief of managing classrooms. Therefore, students are able to interpret what is good to be used in classrooms and what is not supposed to be done in classrooms.

Such a design may also be applicable for teaching other subjects in varied fields. Due to the limited research on the application of experiential learning cycle in English Department of undergraduate students, similar research is therefore open for further investigation. This research limitation lies on the method of investigation which is a descriptive study and the limited number of students involved in this study. Future research should include the evaluation of such a design, experiments, and perceptions of both teachers and students on the experiential learning cycle in different fields.

\section{REFERENCES}

[1] Travers, A., \& Decker, E. (1999). New Technology and Critical Pedagogy. Radical Peagogy, 1(2).

[2] Ruben, B. D. (1999). Simulations, Games, and Experience-Based Learning: The Quest for a New Paradigm for Teaching and Learning. Aimulation \& Gaming, 30(4), 498-505. 
[3] Kolb, D., \& Fry, R. (1975). Toward an applied theory of experiential learning. In C. Cooper, Theories of group processes (pp. 33-57). New York: John Wiley \& Sons.

[4] Dehaan, J., Johnson, N. H., Yoshimura, N., \& Kondo, T. (2012). Wiki and Digital Video Use in Strategic Interaction-based Experiential EFL Learning. CALICO Journal, 29(2), 249-268.

[5] Miles, W. G., Biggs, W. D., \& Schubert, J. N. (1986). Student Perceptions of skill Acquisition through Cases and a General Management Simulation: A Comparison. SIMULATION \& GAMES, 17(1), 7-24.

[6] Feinstein, A. H. (2001). An Assessment of the Effectiveness of Simulation as an Instructional System in Foodservice. Hospitality \& Tourism Research, 25(4), 421-443.

[7] Yeo, R. K., \& Marquardt, M. J. (2015). (Re) Interpreting Action, Learning, and Experience: Integrating Action Learning and Experiential Learning for HRD. Human Resource Development Quarterly, 26(1), 81-107

[8] Holman, D., Pavlica, K., \& Thorpe, R. (1997). Rethinking Kolb’s Theory of Experiential Learning in Management Education: The Contribution of Social Constructionism and Activity Theory. Management Learning, 28(2), 135-148. https://doi.org/10.1177/1350507697282003

[9] Healey, M., \& Jenkins, A. (2000). Kolb's Experiential Learning Theory and Its Application in Geography, in Higher Education. The Journal of Geography, 99(5), 185-195.

[10] Jarmon, L., Traphagan, T., Mayrath, M., \& Trivedi, A. (2009). Virtual world teaching, experiential learning, and assessment: An interdisciplinary communication course in Second Life. Computers \& Education, 53, 169-182.

[11] Joshi, M., Davis, E. B., Kathuria, R., \& Weidner, C. K. (2005). Experiential Learning Process: Exploring Teaching and Learning of Strategic Mangament Framework through the Winter Survival Exercise. Journal of Management Education, 29(5), 672-695.

[12] Kolb, D. A. (1984). Experiential Learning: Experience as the source of learning and development. New Jersey: Prentice Hall.

[13] Silberman, M. L. (2007). Introducing The Handbook of Experiential Learning. In M. S. Silberman (Ed.), The Handbook of Experiential Learning (pp. 1-10). San Francisco: John Wiley \& Sons, Inc.

[14] Chilcott, J. D. (1996, July 9). Effective Use of Simulations in the Classroom. Creative Learning Exchange. Retrieved from www.clexchange.org

[15] Hoover, J. D., \& Whitehead, C. J. (1975). An Experiential-Cognitive Methodology in the First Course in Management: Some Preliminary Results. Simulation Games and Experiential Learning in Action, 2, 25-30.

[16] Bartle, E. (2015, March 23-24). Experiential Learning: an overview. Italy. 